\title{
Night Eating Syndrome According to Obesity Groups and the Related Factors
}

\author{
Yasin Kara, Sabah Tuzun, Can Oner and Engin Ersin Simsek \\ Department of Family Medicine, University of Health Sciences, Istanbul Kartal Dr. Lutfi Kirdar Training and Research Hospital, \\ Istanbul, Turkey
}

\begin{abstract}
Objective: To find the frequency of night eating syndrome (NES) in different obesity groups and to determine related factors.

Study Design: Descriptive cross-sectional study.

Place and Duration of Study: Department of Family Medicine, Outpatient Clinics, University of Health Sciences, Kartal Dr. Lutfi Kirdar Training and Research Hospital from December 2018 to January 2019.

Methodology: Participants were divided into class I, class II, and class III obesity groups according to their BMI levels and administered a survey evaluating their sociodemographic features and a NES questionnaire.

Results: NES was detected in 92 (21.85\%) of all participants; whereas, 28 participants (18.67\%) of class I obesity group, 32 participants $(22.70 \%)$ of class II obesity group and 32 participants $(24.62 \%)$ of class III obesity group had NES ( $p=0.465)$. There was no significant difference between individuals with and without NES in terms of age, gender, marital status, income level, occupational status, presence of children, living-together subjects, cigarette consumption, BMI, waist-hip ratio, and waist-height ratio. However, within the class I obesity group, the likelihood of weight loss was significantly lower among participants with NES $(p=0.026)$. There was no relationship between NES and the duration of obesity, dieting, and the number of main meals per day. However, the relationship between NES and the number of snacks per day was significant in class I and III obesity groups $(p=0.040$ and $p=0.034$, respectively).

Conclusion: The frequency of NES was found to be high in all obesity groups with no significant difference across groups. Therefore, all obese patients should be evaluated in terms of NES, and nutritional recommendations should be provided in the treatment of obesity.
\end{abstract}

Key Words: Morbid obesity, Night eating syndrome, Obesity.

How to cite this article: Kara Y, Tuzun S, Oner C, Simsek EE. Night Eating Syndrome According to Obesity Groups and the Related Factors. J Coll Physicians Surg Pak 2020; 30(08):833-838.

\section{INTRODUCTION}

Night eating syndrome (NES) was first defined in 1955 as the lack of appetite in the morning, hyperphagia in the evening, and difficulty in falling asleep and maintaining sleep in obese people, who do not respond to the treatment as requested. ${ }^{1,2}$ It has been found that disturbance between the sleep and eating patterns as well as shifts in the biological hour of eating occurred in individuals diagnosed with NES., Delays in mealtimes and waking up at night to eat may cause loss of appetite in breakfast. ${ }^{2}$ The rhythm between eating and sleeping is delayed for between two and six hours in patients with NES. ${ }^{3}$

Correspondence to: Dr. Yasin Kara, Department of Family Medicine, University of Health Sciences, Istanbul Kartal Dr. Lutfi Kirdar Training and Research Hospital, Istanbul, Turkey

E-mail: dryasnkara@gmail.com

Received: November 27, 2019; Revised: July 17, 2020;

Accepted: July 27, 2020

DOI: https://doi.org/10.29271/jcpsp.2020.08.833
Although there are studies showing association with the presence of NES and obesity, ${ }^{1,2,5-7}$ there are also studies demonstrating the contrary. ${ }^{4,8}$ In addition, the prevalence of NES varies widely due to the lack of a consensus in diagnostic criteria. ${ }^{1}$ The prevalence of NES in healthy adults is between $0.5-1.5 \%$, while this rate varies between $8.9-14 \%$ in obese individuals. ${ }^{1}$

Obesity has become the disease of the current era due to wide adoption of passive lifestyles and incorrect eating habits. Prior research has not conclusively identified the relationship between obesity and NES vis-à-vis underlying factors. Any new insights will contribute to the obesity prevention efforts.

The aim of this study was to evaluate NES prevalence across obesity groups and to determine the variation of socio-demographic, nutritional, and anthropometric factors among obesity groups in the presence of NES.

\section{METHODOLOGY}

Participants aged above 18 years with a body mass index (BMI) of $30 \mathrm{Kg} / \mathrm{m}^{2}$ who were admitted to the obesity outpatient clinic, Department of Family Medicine, University of Health Sciences, 
Kartal Dr. Lutfi Kirdar Training and Research Hospital, between December 2018 and January 2019 were included in the study. The study protocol was approved by the Ethics Committee of University of Health Sciences, Kartal Dr Lutfi Kirdar Training and Research Hospital (Ethics Committee Decision No: 2018/514/140/13). Patients with Cushing's syndrome, pregnancy, chronic liver disease, chronic kidney disease as well as individuals working the night shift were excluded from the study.

A sociodemographic form, prepared by the researchers, and the night eating questionnaire were administered to all the participants using face-to-face technique by the same researcher. In the sociodemographic form, administered to the participants, age, gender, marital status, educational level, occupational status, presence of children, living-together subjects, income level, person preparing meals, cigarette consumption, duration of obesity, dietstatus, history of voluntary weight loss in the last 6 months, and the number of main meals and snacks per day of all the participants were evaluated. Moreover, waist circumference, hip circumference, body weight, and height were measured and then BMI was calculated using the body weight $(\mathrm{Kg}) /$ height $(\mathrm{m})^{2}$ formula. Participants with a BMI of 30.00-34.99 $\mathrm{Kg} / \mathrm{m}^{2}$ were included in class I obesity group; whereas, those with a BMI of $35.00-39.00 \mathrm{Kg} / \mathrm{m}^{2}$ in class II obesity group, and those with a BMI of $40.00 \mathrm{Kg} / \mathrm{m}^{2}$ in class III obesity group. ${ }^{9}$

Night eating questionnaire developed by Allison et al. consisted of four sub-dimensions (evening hyperphagia, night eating, loss of appetite in the morning, mood and sleep disorder) and a total of 14 items. ${ }^{10}$ The night eating questionnaire, which has a Turkish validity and reliability study, is scored between 0 and 52 points. ${ }^{11}$ The first nine items of the questionnaire are administered to all participants; whereas, the following items are only asked to participants waking up at night. The items 10, 11 and 12 of the questionnaires are administered to participants waking up at night, while items 13 and 14 are asked to participants having night snacks. In the questionnaire, all items except the seventh item, are scored with a 5-point Likert scale whereas 0 points are given to those without any mood swings in the seventh item investigating mood swings. Items 1, 4 and 14 of the questionnaires are scored inversely according to Likert scale. In addition, the 13th item evaluating the awareness of participants about night snacks is not included in the scoring. In the validity and reliability study regarding the night eating questionnaire, the cut-off value was considered as 18 points and the sensitivity and specificity of this questionnaire were $90.7 \%$ and $73.8 \%$ respectively using this cut-off value. $^{11}$

Data were analysed using SPSS22.0 programme. The data were presented as descriptive statistical methods such as percentages and frequencies, mean \pm standard deviation, and median (interquartile range, i.e., Q1-Q3). Moreover, one-way ANOVA test, Studentt-test, and Pearson correlation analysis were used for normal variables with normal distribution; whereas, Kruskal Wallis test, Mann-Whitney U-test, and Spearman correlation analysis were used for continuous variables with abnormal distribution. For pairs of quantitative variables with outliers and nonlinearity, we reported the Spearman correlation. In such cases, those quantitative variables were converted to ranks for the purpose of computing the Spearman correlation. Categorical variables were analysed using Chi-Square test, Fisher's Exact test, and Pearson Chi-square test. Ap-value less than 0.05 was considered significant.

\section{RESULTS}

A total of 421 obese patients were included in the study: 150 (35.63\%) participants in the class I obesity group, 141 (33.49\%) in the class II obesity group, and 130 (30.88\%) in the class III obesity group. Socio-demographic characteristics of participants according to obesity groups are summarised in Table I. There was a significant difference between class I and II obesity groups in terms of gender of the participants among obesity groups; whereas, there was no any significant difference between class II and III obesity groups ( $p=0.027$ and $p=0.224$, respectively).

Mean BMI was $32.40 \pm 1.34 \mathrm{~kg} / \mathrm{m}^{2}$ in the class I obesity group, $37.36 \pm 1.34 \mathrm{~kg} / \mathrm{m}^{2}$ in the class II obesity group and, $44.97 \pm 4.63$ $\mathrm{Kg} / \mathrm{m}^{2}$ in the class III obesity group $(\mathrm{p}<0.001)$. Anthropometric and nutritional features of participants according to obesity groups are summarised in Table II. When anthropometric measurements were evaluated among obesity groups using ttests (normally distributed with equal variance), there was no significant difference between class I and class II obesity groups, and class II and class III obesity groups in terms of waist-hip ratio whereas there was a significant difference in terms of waistheight ratio (respectively, $p=0.868$ and $p=0.545$ for waist-hip ratio; $p<0.001$ and $p<0.001$ for waist-height ratio). Moreover, obesity duration was evaluated using Mann-Whitney test, resulting in significant differences between class I and class II obesity groups as well as between class II and class III obesity groups $(p=0.002$ and $p<0.001$, respectively).

It was observed that $92(21.85 \%)$ participants in the study had NES, with 28 (18.67\% out of 150) of participants in the class I obesity group, $32(22.70 \%$ out of 141$)$ in the class II obesity group, and 32 (24.62\% out of 130 ) in the class III obesity group ( $p$ $=0.465)$. There was no significant difference gender, income level, occupational status, presence of children, living-together subjects, person preparing meals, and cigarette consumption in terms of NES presence in all obesity groups. On the other hand, there was a significant difference in the marital status for class I obesity group with respect to NES $(p=0.024)$ primarily due to a higher prevalence of NES in the single cohort while class II and III groups displayed no significance $(p=0.992$ and $p=0.700$, respectively). Furthermore, educational levels of participants in class I obesity group revealed that 5 (17.86\% out of 28 ) with NES had primary school or below education and 23 (82.14\% out of 28$)$ had secondary school or above education whereas there was no significant difference between participants with and without NES in class II and III obesity groups in terms of educational level $(p<0.001, p=0.169$, and $p=0.946$, respectively). Age, anthropometric and nutritional features of obesity groups according to NES are summarised in Table III. 
Table I: Socio-demographic characteristics of participants, according to obesity groups.

\begin{tabular}{|c|c|c|c|c|}
\hline & \multicolumn{3}{|c|}{ Obesity groups } & \multirow[b]{2}{*}{$\mathbf{p}$} \\
\hline & $\begin{array}{c}\text { Class I } \\
(n=150)\end{array}$ & $\begin{array}{l}\text { Class II } \\
(n=141)\end{array}$ & $\begin{array}{l}\text { Class III obesity } \\
\text { (n = 130) }\end{array}$ & \\
\hline Age (years) & $49.49 \pm 12.49$ & $48.43 \pm 11.81$ & $49.05 \pm 11.40$ & $0.747 *$ \\
\hline $\begin{array}{l}\text { Gender: } \\
\text { Male } \\
\text { Female }\end{array}$ & $\begin{array}{c}38(25.33) \\
112(74.67)\end{array}$ & $\begin{array}{c}21(14.89) \\
120(85.11)\end{array}$ & $\begin{array}{c}13(10.00) \\
117(90.00)\end{array}$ & $0.002 * *$ \\
\hline $\begin{array}{l}\text { Education: } \\
\text { Primary school and lower } \\
\text { Higher than primary school }\end{array}$ & $\begin{array}{l}73(48.67) \\
77(51.33)\end{array}$ & $\begin{array}{l}81(57.45) \\
60(42.55)\end{array}$ & $\begin{array}{l}90(69.23) \\
40(30.77)\end{array}$ & $0.002 * *$ \\
\hline $\begin{array}{l}\text { Marital status: } \\
\text { Single } \\
\text { Married } \\
\text { Divorced/widow }\end{array}$ & $\begin{array}{c}16(10.67) \\
122(81.33) \\
12(8.00)\end{array}$ & $\begin{array}{c}9(6.38) \\
118(83.69) \\
14(9.93)\end{array}$ & $\begin{array}{c}9(6.92) \\
104(80.00) \\
17(13.08)\end{array}$ & $0.426 * *$ \\
\hline $\begin{array}{l}\text { Income level: } \\
\text { Minimum wage and lower } \\
\text { Higher than minimum wage }\end{array}$ & $\begin{array}{c}42(28.00) \\
108(72.00)\end{array}$ & $\begin{array}{l}46(32.62) \\
95(67.38)\end{array}$ & $\begin{array}{l}45(34.62) \\
85(65.38)\end{array}$ & $0.469 * *$ \\
\hline $\begin{array}{l}\text { Occupational status: } \\
\text { Retired or not working } \\
\text { Working }\end{array}$ & $\begin{array}{c}109(72.67) \\
41(27.33)\end{array}$ & $\begin{array}{l}116(82.27) \\
25(17.73)\end{array}$ & $\begin{array}{l}113(86.92) \\
17(13.08)\end{array}$ & $0.009 * *$ \\
\hline $\begin{array}{l}\text { Presence of children: } \\
\text { No } \\
\text { Yes }\end{array}$ & $\begin{array}{c}25(16.67) \\
125(83.33)\end{array}$ & $\begin{array}{c}14(9.93) \\
127(90.07)\end{array}$ & $\begin{array}{c}14(10.77) \\
116(89.23)\end{array}$ & $0.168^{* *}$ \\
\hline $\begin{array}{l}\text { Living-together person: } \\
\text { Alone } \\
\text { Partner } \\
\text { Children } \\
\text { Partner and children } \\
\text { Other }\end{array}$ & $\begin{array}{c}9(6.00) \\
35(23.33) \\
10(6.67) \\
83(55.33) \\
13(8.67)\end{array}$ & $\begin{array}{c}4(2.84) \\
25(17.73) \\
12(8.51) \\
91(64.54) \\
9(6.38)\end{array}$ & $\begin{array}{c}4(3.08) \\
24(18.46) \\
15(11.54) \\
76(58.46) \\
11(8.46)\end{array}$ & $0.523^{* *}$ \\
\hline $\begin{array}{l}\text { Person preparing meals: } \\
\text { Himself/herself } \\
\text { Children } \\
\text { Partner } \\
\text { Mother }\end{array}$ & $\begin{array}{c}108(72.00) \\
4(2.67) \\
28(18.67) \\
10(6.67) \\
\end{array}$ & $\begin{aligned} & 117(82.98) \\
& 2(1.42) \\
& 15(10.64) \\
& 7(4.96) \\
&\end{aligned}$ & $\begin{array}{c}112(86.15) \\
3(2.31) \\
9(6.92) \\
6(4.62) \\
\end{array}$ & $0.076 * *$ \\
\hline $\begin{array}{l}\text { Cigarette consumption: } \\
\text { No } \\
\text { Yes } \\
\text { Quit }\end{array}$ & $\begin{array}{l}93(62.00) \\
27(18.00) \\
30(20.00)\end{array}$ & $\begin{array}{l}94(66.67) \\
16(11.35) \\
31(21.99)\end{array}$ & $\begin{array}{l}80(61.54) \\
24(18.46) \\
26(20.00)\end{array}$ & $0.506^{* *}$ \\
\hline
\end{tabular}

Table II: Anthropometric and nutritional features of participants according to obesity groups.

\begin{tabular}{|c|c|c|c|c|}
\hline & \multicolumn{3}{|c|}{ Obesity groups } & \multirow{2}{*}{$\mathbf{p}$} \\
\hline & Class I $(n=150)$ & Class II $(n=141)$ & Class III obesity $(n=130)$ & \\
\hline Waist-hip ratio & $0.93 \pm 0.07$ & $0.93 \pm 0.08$ & $0.92 \pm 0.07$ & $0.709 *$ \\
\hline Waist-height ratio & $0.63 \pm 0.04$ & $0.69 \pm 0.05$ & $0.76 \pm 0.07$ & $<0.001 *$ \\
\hline Duration of obesity (years) & $10(5-19)$ & $12(8-20)$ & $20(10.75-26.25)$ & $<0.001^{\dagger}$ \\
\hline $\begin{array}{l}\text { Dieting: } \\
\text { No } \\
\text { Yes }\end{array}$ & $\begin{array}{l}58(38.7) \\
92(61.3)\end{array}$ & $\begin{array}{l}45(31.9) \\
96(68.1)\end{array}$ & $\begin{array}{l}38(29.2) \\
92(70.8)\end{array}$ & $0.221 * *$ \\
\hline $\begin{array}{l}\text { Weight loss: } \\
\text { No } \\
\text { Yes }\end{array}$ & $\begin{array}{l}90(60.0) \\
60(40.0)\end{array}$ & $\begin{array}{l}81(57.4) \\
60(42.6)\end{array}$ & $\begin{array}{l}73(56.2) \\
57(43.8)\end{array}$ & $0.800 * *$ \\
\hline Number of main meals per day & $3(2-3)$ & $3(2-3)$ & $2(2-3)$ & $0.770^{\dagger}$ \\
\hline Number of snacks per day & $1(0 .-2)$ & $1(0 .-2)$ & $1(0-2)$ & $0.514^{\dagger}$ \\
\hline
\end{tabular}

Table III: Age, anthropometric and nutritional features of obesity groups according to the presence of NES. 


\begin{tabular}{|c|c|c|c|c|c|c|c|c|c|}
\hline & \multirow{2}{*}{\multicolumn{2}{|c|}{$\begin{array}{c}\text { Class I Obesity Group } \\
\text { NES }\end{array}$}} & \multirow{3}{*}{$\mathbf{p}$} & \multirow{2}{*}{\multicolumn{2}{|c|}{$\begin{array}{c}\text { Class II Obesity Group } \\
\text { NES }\end{array}$}} & \multirow{3}{*}{$\mathbf{p}$} & \multirow{2}{*}{\multicolumn{2}{|c|}{$\begin{array}{c}\text { Class III Obesity Group } \\
\text { NES }\end{array}$}} & \multirow{3}{*}{$\mathbf{p}$} \\
\hline & & & & & & & & & \\
\hline & No $(n=122)$ & Yes $(n=28)$ & & No $(n=109)$ & Yes $(n=32)$ & & No $(n=98)$ & Yes $(n=32)$ & \\
\hline Age (years) & $50.28 \pm 12.14$ & $46.07 \pm 13.62$ & $0.141^{*}$ & $49.66 \pm 11.41$ & $44.22 \pm 12.37$ & $0.031^{*}$ & $49.76 \pm 10.62$ & $46.88 \pm 13.47$ & $0.276 *$ \\
\hline BMI $\left(\mathrm{Kg} / \mathrm{m}^{2}\right)$ & $32.40 \pm 1.36$ & $32.39 \pm 1.32$ & $0.958^{*}$ & $37.30 \pm 1.34$ & $37.55 \pm 1.35$ & $0.370^{*}$ & $44.77 \pm 4.69$ & $45.57 \pm 4.46$ & 0.393* \\
\hline Waist-hip ratio & $0.93 \pm 0.07$ & $0.93 \pm 0.08$ & $0.677^{*}$ & $0.93 \pm 0.08$ & $0.92 \pm 0.08$ & $0.529^{*}$ & $0.93 \pm 0.08$ & $0.91 \pm 0.06$ & $0.237 *$ \\
\hline Waist-height ratio & $0.63 \pm 0.04$ & $0.63 \pm 0.04$ & $0.922^{*}$ & $0.69 \pm 0.05$ & $0.68 \pm 0.05$ & $0.155^{*}$ & $0.76 \pm 0.07$ & $0.76 \pm 0.08$ & $0.962 *$ \\
\hline $\begin{array}{l}\text { Duration of obesity } \\
\text { (years) }\end{array}$ & $\begin{array}{c}10.00 \\
(5.00-17.50)\end{array}$ & $\begin{array}{c}7.50 \\
(5.00-19.75)\end{array}$ & $0.302^{* *}$ & $\begin{array}{c}15.00 \\
(10.00-24.00)\end{array}$ & $\begin{array}{c}10.00 \\
(6.125-15.00)\end{array}$ & $0.062^{* *}$ & $\begin{array}{c}20.00 \\
(14.50-27.00)\end{array}$ & $\begin{array}{c}17.50 \\
(10.00-25.00)\end{array}$ & $0.274 * *$ \\
\hline $\begin{array}{l}\text { Dieting: } \\
\text { No } \\
\text { Yes }\end{array}$ & $\begin{array}{l}43(35.25) \\
79(64.75)\end{array}$ & $\begin{array}{l}15(53.57) \\
13(46.43)\end{array}$ & $0.073^{\dagger}$ & $\begin{array}{l}32(29.36) \\
77(70.64)\end{array}$ & $\begin{array}{l}13(40.63) \\
19(59.37)\end{array}$ & $0.229^{\dagger}$ & $\begin{array}{l}27(27.55) \\
71(72.45)\end{array}$ & $\begin{array}{l}11(34.38) \\
21(65.62)\end{array}$ & $0.461^{\dagger}$ \\
\hline $\begin{array}{l}\text { Weight loss: } \\
\text { No } \\
\text { Yes }\end{array}$ & $\begin{array}{l}68(55.74) \\
54(44.26)\end{array}$ & $\begin{array}{l}22(78.57) \\
6(21.43)\end{array}$ & $0.026^{\dagger}$ & $\begin{array}{l}63(57.80) \\
46(42.20)\end{array}$ & $\begin{array}{l}18(56.25) \\
14(43.75)\end{array}$ & $0.876^{\dagger}$ & $\begin{array}{l}52(53.06) \\
46(46.94)\end{array}$ & $\begin{array}{l}21(65.63) \\
11(34.37)\end{array}$ & $0.214^{\dagger}$ \\
\hline $\begin{array}{l}\text { Number of main } \\
\text { meals per day }\end{array}$ & $\begin{array}{c}3.00 \\
(2.00-3.00) \\
\end{array}$ & $\begin{array}{c}2.00 \\
(2.00-3.00) \\
\end{array}$ & $0.074^{* *}$ & $\begin{array}{c}3.00 \\
(2.00-3.00)\end{array}$ & $\begin{array}{c}2.50 \\
(2.00-3.00) \\
\end{array}$ & $0.914^{* *}$ & $\begin{array}{c}2.00 \\
(2.00-3.00) \\
\end{array}$ & $\begin{array}{c}2.50 \\
(2.00-3.00) \\
\end{array}$ & $0.882^{* *}$ \\
\hline $\begin{array}{l}\text { Number of snacks per } \\
\text { day }\end{array}$ & $\begin{array}{c}1.00 \\
(0.00-2.00)\end{array}$ & $\begin{array}{c}0.00 \\
(0.00-1.75)\end{array}$ & $0.040^{* *}$ & $\begin{array}{c}1.00 \\
(0.00-2.00)\end{array}$ & $\begin{array}{c}0.00 \\
(0.00-2.00)\end{array}$ & $0.216^{* *}$ & $\begin{array}{c}1.00 \\
(0.00-2.00)\end{array}$ & $\begin{array}{c}0.00 \\
(0.00-1.75)\end{array}$ & $0.034^{* *}$ \\
\hline
\end{tabular}

The score of night eating questionnaire was $13.05 \pm 5.84$ in the class I obesity group, $13.82 \pm 6.15$ in the class II obesity group, and $14.22 \pm 5.86$ in the class III obesity group ( $p=$ 0.240 ). No significant relationship was found between the questionnaire score and the three anthropometric measurement in all obesity groups $(p>0.05)$. In addition, there was no significant association with questionnaire score and duration of obesity in class I and class III obesity groups whereas a similar correlation was found in class II obesity group ( $p$ $>0.05 ; r=-0.242$ and, $p=0.004$, respectively). In all obesity groups, no significant correlation was found between the questionnaire score and the number of main meals per day $(r=-0.078 p=0.344, r=-0.131 p=0.121$, and $r=0.047 p$ $=0.597$, respectively). However, in class I obesity group, a significant correlation was found between the questionnaire score and the number of snacks per day whereas no similar correlation was found between class II and class III obesity groups ( $r=-0.180$ and $p=0.028 ; p>0.05$, respectively).

\section{DISCUSSION}

This study aimed to find out prevalence of NES according to obesity groups and determine the related factors. The prevalence of NES was measured to be $21.85 \%$ for all the participants. There was no significant difference between groups; whereas, the prevalence of NES by obesity groups was $18.67 \%$ for class I obesity group, $22.70 \%$ for class II obesity group, and $24.62 \%$ for class II obesity group. There were no significant differences for gender, marital status, occupational status, income level, living-together subjects, person preparing meals, and cigarette consumption in terms of NES presence among all obesity groups. On the other hand, the participants with higher education had higher prevalence of NES in class I obesity group; whereas, no significant difference with respect to educational levels was observed in class II and class III obesity groups. There was no significant difference between participants with or without NES in all obesity groups in terms of BMI, waist-hip and waist-height ratios. In addition, the duration of obesity and the number of main meals per day were low in all obesity groups; whereas, no statistical significance was observed. Although the number of snacks per day in participants with NES was low in all obesity groups, this difference was found to be significant in class I and class III obesity groups.

The link between obesity and NES is controversial. ${ }^{1,2,4,6-8}$ Although the prevalence of NES is found to be higher in obese individuals in some studies, ${ }^{1,2,6,7}$ there are studies showing the contrary. ${ }^{4,8}$ While the prevalence of NES is between $0.5-1.5 \%$ in adult individuals, this rate varies between $8-15 \%$ in obese individuals. ${ }^{1,12}$ The prevalence of NES was found to be $10.1 \%$ in a study conducted with class II and class III obese individuals. ${ }^{7}$ Moreover, it was observed that there was an increase in obesity level and prevalence of NES. ${ }^{1}$ The prevalence of NES was found to be $15 \%$ in obese individuals and $42 \%$ in morbidly obese individuals. ${ }^{13,14}$ The prevalence of NES in obese individuals was found to be $21.85 \%$ in the present study. When evaluated among all obesity groups, the prevalence of NES was found to $18.67 \%$ in the class I obesity group, $22.70 \%$ in the class II obesity group, and $24.62 \%$ in the class III obesity group; whereas, there was no any significant difference regarding the prevalence of NES according to obesity groups.

There was no any relationship between the presence of NES and age in some studies; ${ }^{4,15}$ whereas, a relationship between two variables was found in another study. ${ }^{6}$ Moreover, NES was found to be higher in women in some studies; ${ }^{5,16}$ whereas, there was no any difference between gender in terms of NES presence in some studies. ${ }^{4,6,7}$ In one study, it was confirmed that night-eating attacks were lower in married individuals compared to single individuals. ${ }^{15}$ There was no significant link was observed between NES and age, marital status and educational level in a study performed in class II and class III obese individuals. ${ }^{7}$ Moreover, there was no any correlation between the presence of NES and income level in a study. In one study, no significant correlation was found between cigarette consumption among individuals with and without eating disorders. ${ }^{14}$ In the present study, no significant difference was found in gender, marital status, 
occupational status, presence of children, living-together subjects, and cigarette consumption in terms of NES presence in all obesity groups. However, secondary and higher education level was significantly high in individuals with NES from class I obesity group; whereas, there was no any significant difference between individuals with or without NES in class II and III obesity groups in terms of educational levels of the participants.

While BMI was found to be high in patients with NES in some studies, ${ }^{2,17,18}$ no similar difference was observed in other studies. ${ }^{4,7,15}$ In a study conducted with class II and class III obese individuals, no significant relationship was found between high BMI and NES presence. ${ }^{7}$ In the present study, no significant difference was found in terms of NES presence, questionnaire score, BMI, waist-hip and waist-height ratios in all obesity groups.

According to a recent study, it was found that NES presence had a role in the duration of obesity and may cause difficulty in weight loss during obesity treatment. ${ }^{7}$ However, no association with NES presence and weight loss was found in a study conducted with class II and III obese individuals. ${ }^{7}$ In another study, no relationship was observed between individuals with or without eating disorders in terms of onset of obesity at an early age. ${ }^{14}$ In this study, no significant difference was found in terms of NES presence, obesity duration, and diet status in all obesity groups. However, while the presence of weight loss was significantly low in the NES group in class I obesity group, no difference was found in class II and class III obesity groups. While the number of main meals per day was low in all obesity groups in individuals with NES, no significant difference was found. The number of snacks per day was low in those with NES in all obesity group whereas it was found to be significant in class I and III obesity groups.

One of the main limitations of this study was that the participants were not evaluated for psychiatric disorders such as depression, which has an important role in the etiopathogenesis of NES. ${ }^{1}$ Another limitation was that both newly admitted patients and patients under treatment and followup in the obesity clinic were evaluated together. This renders it difficult to evaluate participants eating habits at night. The nutritional habits of patients are rearranged in obesity treatment, and regular daily meals and snacks are recommended.

\section{CONCLUSION}

There was no correlation between obesity and NES. The frequency of NES was higher in obese individuals compared to normal-weight individuals. NES was observed more frequently as BMI increased in obesity groups. Evaluation of eating disorders such as NES is required for the obesity treatment.

\section{CONFLICT OF INTEREST:}

Authors declared no conflict of interest.

\section{ETHICAL APPROVAL:}

The study protocol was approved by the Ethics Committee of University of Health Sciences, Kartal Dr. Lutfi Kirdar Training and Research Hospital (Ethics Committee Decision No: 2018/514/140/13).

\section{PATIENTS' CONSENT:}

Informed consents were obtained from all patients to publish the data concerning their case.

\section{AUTHORS' CONTRIBUTION:}

YK: Data acquisition and analysis, interpretation, drafting and final approval.

ST: Conception and design, analysis and interpretation of data and drafting of manuscript.

CO: Conception and design, critical revision and final approval.

EES: Conception and design, analysis and interpretation of data, critical revision and final approval.

\section{REFERENCES}

1. Cleator J, Abbott J, Judd P, Sutton C, Wilding JPH. Night eating syndrome: Implications for severe obesity. Nutr Diabetes 2012; 2(9):e44. doi: 10.1038/nutd.2012.16.

2. McCuen-Wurst C, Ruggieri M, Allison KC. Disordered eating and obesity: Associations between binge eating-disorder, night-eating syndrome, and weight-related co-morbidities. Ann N Y Acad Sci 2018; 1411(1):96-105. doi: 10.1111/ nyas.13467.

3. Stunkard AJ, Allison KC, O'Reardon JP. The night eating syndrome: a progress report. Appetite 2005; 45(2):182-6. doi: 10.1016/j.appet.2005.01.013.

4. Öner C, Günay N, Telatar B, Yeşildağ Ş. Night eating syndrome in young adolescents: Frequency and significance. Anatol JFM 2018; 1:17-20. doi:10.5505/anato ljfm.2018.32042.

5. Aronoff NJ, Geliebter A, Zammit G. Gender and body mass index as related to the night-eating syndrome in obese outpatients. J Am Diet Assoc 2001; 101(1):102-4. doi: 10.1016/S0002-8223(01)00022-0.

6. Öztürk GZ, Eğici MT, Toprak D, Erdoğan AM. Relationship between night eating disorders and obesity. Ankara Med J 2018; 1:117-22.

7. Calugi S, Dalle Grave R, Marchesini G. Night eating syndrome in class II-III obesity: metabolic and psychopathological features. Int J Obes 2009; 33(8): 899-904. doi: 10.1038/ijo.2009.105.

8. Striegel-Moore RH, Franko DL, Thompson D, Affenito S, Kraemer HC. Night eating: Prevalence and demographic correlates. Obesity (Silver Spring) 2006; 14(1):139-47. doi: 10.1038/oby.2006.17.

9. http://www.who.int/dietphysicalactivity/childhood_what/en/ [Accessed on 01 July 2019].

10. Allison KC, Lundgren JD, O'Reardon JP, Martino NS, Sarwer DB, Wadden TA, et al. The night eating questionnaire (neq): Psychometric properties of a measure of severity of the 
night eating syndrome. Eat Behav 2008; 9(1):62-72. doi: 10.1016/j.eatbeh.2007.03.007.

11. Atasoy N, Saraçlı Ö, Konuk N, Ankaralı H, Güriz SO, Akdemir $A$, et al. The reliability and validity of Turkish version of the night eating questionnaire in psychiatric outpatient population. Anatolian J Psychiatry 2014; 15:238-47.

12. Ceru-Björk C, Andersson I, Rössner S. Night eating and nocturnal eating-two different or similar syndromes among obese patients? Int J Obes Relat Metab Disord 2001; 25(3):365-72. doi: 10.1038/sj.ijo.0801552.

13. Stunkard AJ, Allison KC. Two forms of disordered eating in obesity: binge eating and night eating. Int J Obes Relat Metab Disord 2003; 27(1):1-12. doi: 10.1038/sj. ijo.0802186.

14. Allison KC, Wadden TA, Sarwer DB, Fabricatore AN, Crerand CE, Gibbons LM, et al. Night eating syndrome and binge eating disorder among persons seeking bariatric surgery: Prevalence and related features. Obesity (Silver Spring)
2006; 14(supp2):77S-82S. doi: 10.1038/oby.2006.286

15. Striegel-Moore RH, Rosselli F, Wilson GT, Perrin N, Harvey K, DeBar L. Nocturnal Eating: Association with binge eating, obesity, and psychological distress. Int J Eat Disord 2010; 43(6):520-6. doi: 10.1002/eat.20735.

16. Allison KC, Lundgren JD, Stunkard AJ, Bulik CM, Lindroos AK, Thornton LM, et al. Validation of screening questions and symptom coherence of night eating in the Swedish Twin Registry. Compr Psychiatry 2014; 55(3):579-87. doi: 10.1016/j.comppsych.2013.01.006.

17. de Zwaan M, Müller A, Allison KC, Brahler E, Hilbert A. Prevalence and Correlates of Night Eating in the German General Population. PLoS One 2014; 9(5):e97667. doi: 10.1371/journal.pone.0097667.

18. Colles SL, Dixon JB, O'Brien PE. Night eating syndrome and nocturnal snacking: Association with obesity, binge eating and psychological distress. Int J Obes (Lond) 2007; 31(11):1722-30. doi: 10.1038/sj.ijo.0803664. 